\title{
Evaluation of poly(2-hydroxyethyl methacrylate) gels as drug delivery systems at different $\mathrm{pH}$ values
}

\author{
L. Ferreira, M.M. Vidal, M.H. Gil* \\ Departamento de Engenharia Química, Universidade de Coimbra, Pinhal de Marrocos, 3030 Coimbra, Portugal
}

Received 24 May 1999; received in revised form 15 October 1999; accepted 15 October 1999

\begin{abstract}
Studies of dynamic and equilibrium swelling, structural characterisation and solute transport in swollen poly(2-hydroxyethyl methacrylate) gels (pHEMA) cross-linked with tripropyleneglycol diacrylate (TPGDA) were done for a wide range of TPGDA concentrations. The influence of the $\mathrm{pH}$ on these pHEMA properties was evaluated. In swelling studies it was found that in changing the $\mathrm{pH}$ from 6.5 to 12.0 , a large increase in swelling occurred, from approximately 48 to $55 \%$, for the lowest concentration of TPGDA ( $1 \mathrm{~mol} \%$ ), and from 40 to $80 \%$ for the highest concentration $(10 \mathrm{~mol} \%)$. Fourier transform infrared (FTIR) and differential scanning calorimetry (DSC) measurements were made after the equilibrium swelling of the gels at different $\mathrm{pH}$ values, to explain these results. The advantage of using these gels as controlled drug delivery systems is illustrated using salicylic acid (SA) as a model drug. The loading and the release of the SA were made at different $\mathrm{pH}$ values and the results obtained showed that it is possible to modulate the hydrogel performance by controlling an external factor, the $\mathrm{pH}$ at which the drug loading and release were performed. (c) 2000 Elsevier Science B.V. All rights reserved.
\end{abstract}

Keywords: Hydroxyethyl methacrylate; Hydrogels; Swelling; Salicylic acid; Controlled release; Structural characterisation

\section{Introduction}

pHEMA gels are very resistant to high temperatures, to acid and alkaline hydrolysis, and they have a low reactivity with amines (Ratner and Hoffman, 1976). Such chemical and thermal stability make pHEMA gels suitable materials for the development of controlled drug delivery systems (Huglin and Sloan, 1983; Denizli et al., 1988;

\footnotetext{
* Corresponding author. Tel.: + 351-239-798700; fax: + 351-239-798703.

E-mail address: hgil@eq.uc.pt (M.H. Gil)
}

Blanco et al., 1994; Garcia et al., 1994; Teijon et al., 1997), and for other biomedical and pharmaceutical applications (Montheard et al., 1992; Peluso et al., 1997).

The release of a drug through a network gel based on pHEMA polymer is strongly affected by the water swelling capacity of the gel. Therefore, swelling ratio changes induced by external conditions ( $\mathrm{pH}$, temperature, ionic strength) are of special importance for controlled release systems, since they offer the possibility of a direct control of drug release at a convenient place and predetermined time. Since the gels of pHEMA are consid- 
ered non-ionic gels, most of the studies reporting $\mathrm{pH}$-sensitive swelling behaviour involve modified pHEMA, either copolymerised with acrylic or methacrylic acids (Bettini et al., 1995; Khare and Peppas, 1995), or pHEMA gels partially hydrolysed with alkali at high temperatures (Svecik et al., 1995). To date, as far we know no work has been reported on the literature showing a $\mathrm{pH}$-sensitive swelling behaviour of unmodified pHEMA gels. Further, no studies have been reported using pHEMA gels as drug delivery systems at different $\mathrm{pH}$ values.

In this work, we have prepared pHEMA gels crosslinked with tripropyleneglycol diacrylate (TPGDA). Water swelling behaviour, DSC and FTIR spectroscopy studies were made of the samples treated at different $\mathrm{pH}$ values, over a wide range of crosslinking agent concentrations. These gels, particularly those prepared with the highest concentrations of crosslinking agent, showed an exceptional $\mathrm{pH}$-sensitivity. The advantage of using these gels to design controlled drug delivery systems is illustrated by using salicylic acid (SA) as a model drug whose loading is possible either for high or low values of $\mathrm{pH}$. The capacity of SA loading and apparent diffusion coefficient through these gels were compared under different conditions.

\section{Materials and methods}

\subsection{Materials}

Hydroxyethyl methacrylate (HEMA) was purchased from ACROS organics (New Jersey, USA) and was vacuum distilled at $65^{\circ} \mathrm{C} / 5 \mathrm{mmHg}$ (Khare and Peppas, 1995); ammonium persulphate and sodium methabisulphite were supplied by May \& Baker (Dagenham, England); tripropyleneglycol diacrylate (TPGDA) was kindly offered by UCB Chemicals; salicylic acid (SA) was purchased from Sigma Chemical Company (England).

\subsection{Methods}

\subsubsection{Gel preparation}

The pHEMA gels were prepared in $10 \mathrm{ml}$ glass beakers (diameter $3 \mathrm{~cm}$ ) by polymerizing the mono functional monomer, HEMA $(200 \mu 1)$ with multifunctional monomer TPGDA $(1-10 \mathrm{~mol} \%$ relative to the monomer) in the presence of a radical initiator, consisting of an ammonium persulphate/ sodium methabisulphite mixture (3 mg, 1:2 w/w), in $1 \mathrm{ml}$ of the ethylene glycol/water 70:30 (v/v) mixture. After homogenisation, solutions were bubbled with $\mathrm{N}_{2}$ gas $(5 \mathrm{~min}$ ), stoppered and the temperature increased to $55^{\circ} \mathrm{C}$. The polymerization reaction proceeded for $4 \mathrm{~h}$. The above procedure followed a modification of the protocol suggested by Refojo and Yasuda (1965).

The resulting gels were kept overnight at room temperature and were subsequently separated from the glass beakers after adding some distilled water. To remove unreacted monomers, gel samples were immersed in distilled water for 5 days, changing the water every day. The gels were then dried at room temperature, under vacuum, in the presence of phosphorous pentoxide, and weighed to determine the dried weight, $W_{\mathrm{d}}$. The pHEMA gels were denoted by: pHEMA1, pHEMA2, pHEMA3, pHEMA4 and pHEMA5 with 1, 2, 3, 5, $10 \mathrm{~mol} \%$ (relative to HEMA monomer) of TPGDA, respectively.

\subsubsection{Gel characterisation}

\subsubsection{Dynamic and equilibrium swelling experi-} ments. The degree of swelling $\left(W_{t}\right)$ in distilled water and in aqueous solutions with different $\mathrm{pH}$ was determined by immersing the gels either in distilled water or in $\mathrm{NaOH} / \mathrm{HCl}$ aqueous solutions of desired $\mathrm{pH}$, in sealed containers, at $25^{\circ} \mathrm{C}$. At regular period of time, they were removed from the aqueous solution, blotted with filter paper to remove surface water, weighed and returned to the same container until weight stabilisation was observed. The $W_{t}$ was determined using Eq. (1) (Corkhill et al., 1987):

$W_{t}=\left(W_{\mathrm{s}}-W_{\mathrm{d}}\right) / W_{\mathrm{s}} \times 100$

where $W_{\mathrm{s}}$ is the weight of swollen gel and $W_{\mathrm{d}}$ is the weight of dry gel. 
The equilibrium degree of swelling $\left(W_{\infty}\right), W_{t}$ for gels in equilibrium, was attained after 1-7 days depending on the degree of cross-linking and the $\mathrm{pH}$ of the aqueous solution.

The volume equilibrium swelling ratio of the different gels, $Q$, was determined as the ratio of the volumes of the swollen and the dry specimens (Bettini et al., 1995). The gels were allowed to swell until equilibrium in aqueous solution of different $\mathrm{pH}$ both in the absence or in the presence of SA (drug concentration of $0.1 \mathrm{~g} / 100 \mathrm{ml}$ ).

\subsubsection{Salicylic acid $(S A)$ release measurements}

Loading of $S A$ at $p H$ 2.5. After equilibrium in distilled water at $\mathrm{pH} 6.5$ or $\mathrm{NaOH}$ aqueous solution at $\mathrm{pH} 12.0$ (see later), swollen gels were immersed for 8 days in $10 \mathrm{ml}$ of a $\mathrm{SA}$ aqueous solution $(0.10 \%, \mathrm{w} / \mathrm{v}), \mathrm{pH} 2.5$ at $25^{\circ} \mathrm{C}$. After blotting, the gels were immersed in $100 \mathrm{ml}$ of distilled water at $37^{\circ} \mathrm{C}$ with magnetic stirring (150 $\mathrm{rpm})$. The released SA was monitored by its UV absorption band at $300 \mathrm{~nm}$ (Garner and Sugden, 1973) until no further changes of absorbance values were observed. These absorbance measurements were converted to SA concentrations using an SA calibration curve, and the total amount of SA released was calculated.

Loading of $S A$ at $p H$ 12.0. After equilibrium in distilled water at $\mathrm{pH} 6.5$, swollen gels were immersed for 8 days in $10 \mathrm{ml}$ of aqueous $\mathrm{NaOH}$ solution containing SA $(0.10 \%, \mathrm{w} / \mathrm{v}), \mathrm{pH} 12.0$ at $25^{\circ} \mathrm{C}$. At this $\mathrm{pH}$, the $\mathrm{SA}$ was present as its corresponding salt, sodium salicylate (SS) (Shane and Routh, 1967). After blotting, the gels were immersed in $100 \mathrm{ml}$ of distilled water, or $\mathrm{HCl}$ aqueous solution at pH 2.0 (see later), with magnetic stirring $(150 \mathrm{rpm})$, at $37^{\circ} \mathrm{C}$. The released SS was monitored at $300 \mathrm{~nm}$, on an UV spectrophotometer, until no further changes of absorbance values were observed. To determine the residual SS concentration, these gels were pulverised, dried at room temperature under vacuum over phosphorous pentoxide, and then washed with $10 \mathrm{ml}$ of a base solution, $\mathrm{pH}$ 12.0. The absorbance of this alkaline solution was determined at $300 \mathrm{~nm}$. Finally, SS loading was calculated by adding the SS residual concentration to the concentration of the SS released.
2.2.2.3. Differential scanning calorimetry (DSC). DSC thermograms were carried out using a Polymer Laboratories DSC apparatus. The gels were dried until constant weight under vacuum in the presence of $\mathrm{P}_{2} \mathrm{O}_{5}$, at $25^{\circ} \mathrm{C}$. Samples with weights between 2 and $5 \mathrm{mg}$ were then sealed into an aluminium pan. An empty aluminium sealed pan was used as reference material. The temperature was raised from 10 to $400^{\circ} \mathrm{C}$ at a heating rate of $10^{\circ} \mathrm{C} / \mathrm{min}$ under nitrogen atmosphere (flow 10 $\mathrm{ml} / \mathrm{min})$.

2.2.2.4. Fourier transform infrared spectroscopy (FTIR). FTIR spectra were recorded on a Nicolet750 spectrometer. The dry samples were powdered, mixed with $\mathrm{KBr}$ and pressed into pellets under reduced pressure. The FTIR spectra were obtained by recording 128 scans between 4000 and $450 \mathrm{~cm}^{-1}$ with a resolution of 2 $\mathrm{cm}^{-1}$.

\section{Results and discussion}

\subsection{Structural characterisation, equilibrium and dynamic swelling studies}

\subsubsection{In distilled water ( $p H$ 6.5)}

The water absorbed by a gel network is quantitatively represented by the equilibrium degree of swelling, $W_{\infty}$, expressed by Eq. (1). The $W_{\infty}$ is the most important single property of a gel, influencing as it does the permeability, mechanical, surface and other properties of the gel (Corkhill et al., 1987).

The Curve $\mathrm{C}$ in Fig. 1 shows the variation of $W_{\infty}$ for pHEMA gels as a function of the crosslinking agent concentration, for gels equilibrated in distilled water at $\mathrm{pH}$ 6.5. The effect of the cross-link density on the $W_{\infty}$ of pHEMA gels follows the expected trend of a decrease in $W_{\infty}$ with increasing cross-link density (Robert et al., 1985; Allen et al., 1992). Table 1 shows the results of the thermal analysis study for these gels (at $\mathrm{pH}$ 6.5). As it can be seen, melting temperatures and enthalpy changes decrease with increasing cross- 
linking agent concentration, showing that less crystalline gels are getting formed. This means that the few amorphous zones present in the gels prepared with less cross-linking agent are free and elastic enough to swell and hold large amounts of water.

According to the literature, there are three different diffusion mechanisms for the transport of water through cross-linked pHEMA gels, which depend on the crosslinker content: a pore flow mechanism for low cross-linking content (approximately $0-2.5 \mathrm{~mol} \%$ ), a water-matrix interaction mechanism for higher cross-linking content (above $4 \mathrm{~mol}^{\%}$ ) and an intermediate mechanism at intermediate cross-linker concentration (Wisniewski et al., 1976). In our study the pHEMA gels prepared fulfill all the above situations.

To study the uptake of water by pHEMA gels, gel discs with $4.8 \pm 0.4 \mathrm{~mm}$ thickness and $13.1 \pm$ $0.5 \mathrm{~mm}$ diameter were employed. As it can be seen in Fig. 2, $W_{\infty}$ was attained at $\approx 40 \mathrm{~h}$, for all cases.

From these results, the fractional swelling, $F_{\mathrm{w}}$, due to water uptake for a controlled diffusion process was calculated using the equation (Garcia et al., 1994):

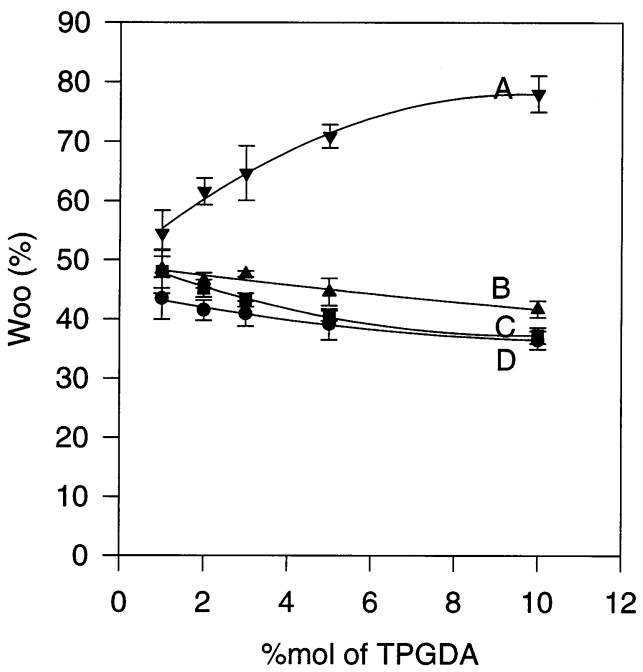

Fig. 1. Equilibrium degree of swelling $(W \infty)$ of pHEMA gels with different concentrations of cross-linker agent (TPGDA), at $25^{\circ} \mathrm{C}$, in different $\mathrm{pH}$ solutions: $\mathrm{pH} 12.0$ (A); $\mathrm{pH} 10.0$ (B); pH 6.5 (C); and pH 2.0 (D). Values of $W \infty$ are given as average and standard deviation over three experiments.
Table 1

Thermal analysis data obtained for pHEMA gels after equilibrium at different $\mathrm{pH}$ solutions

\begin{tabular}{llccc}
\hline pH & Gel & $T_{\mathrm{g}}\left({ }^{\circ} \mathrm{C}\right)$ & $T_{\mathrm{m}}\left({ }^{\circ} \mathrm{C}\right)$ & $\Delta H_{\mathrm{f}}(\mathrm{mCal} / \mathrm{mg})$ \\
\hline \multirow{2}{*}{6.5} & pHEMA1 & 88.1 & 365.0 & 113.2 \\
& pHEMA2 & $-^{\mathrm{a}}$ & $-^{\mathrm{a}}$ & $-^{\mathrm{a}}$ \\
& pHEMA3 & 79.2 & 366.4 & 90.3 \\
& pHEMA4 & 77.5 & 375.5 & 80.5 \\
& pHEMA5 & 68.7 & 369.8 & 78.3 \\
$12.0^{\mathrm{c}}$ & pHEMA1 & $-{ }^{\mathrm{b}}$ & 317.6 & 9.6 \\
& pHEMA2 & $-{ }^{\mathrm{b}}$ & 321.5 & 8.1 \\
& pHEMA3 & $--^{\mathrm{b}}$ & 327.2 & 5.7 \\
& pHEMA4 & $-{ }^{\mathrm{a}}$ & $-{ }^{\mathrm{a}}$ & $-{ }^{\mathrm{a}}$ \\
& pHEMA5 & $-{ }^{\mathrm{b}}$ & 339.8 & 1.9 \\
& & & & \\
& pHEMA1 & 100.0 & 353.0 & 93.0 \\
& pHEMA2 & 95.5 & 357.9 & 87.1 \\
& pHEMA3 & 92.6 & 360.9 & 91.3 \\
& pHEMA4 & 88.8 & 363.4 & 80.8 \\
& pHEMA5 & 84.1 & 367.0 & 69.7
\end{tabular}

${ }^{a}$ Not determined.

${ }^{\mathrm{b}}$ Difficulty in the determination.

c The gels were transferred from a solution at $\mathrm{pH} 6.5$ to an aqueous $\mathrm{NaOH}$ solution $\mathrm{pH} 12.0$ and they were allowed to reach the equilibrium. After, they were dried and DSC studies were made.

d The gels were transferred from a solution at $\mathrm{pH} 12.0$ to an aqueous $\mathrm{HCl}$ solution $\mathrm{pH} 2.0$ and they were allowed to reach the equilibrium. After, they were dried and DSC studies were made.

$F_{\mathrm{w}}=W_{t} / W_{\infty}=4\left(D_{\mathrm{w}} t / l_{\mathrm{o}}^{2} \pi\right)^{1 / 2}$

Here, $D_{\mathrm{w}}$ is the apparent diffusion coefficient for the transport of water into the gel, $t$ is the time and $l_{\mathrm{o}}$ is the thickness of the dried gel. Linearity between $F_{\mathrm{w}}$ and $t^{1 / 2}$ was found for values of $F_{\mathrm{w}}$ less than 0.6 at constant temperature $T$ and fixed $l_{\mathrm{o}}$, so $D_{\mathrm{w}}$ can be obtained from the slope (Crank, 1975). The $D_{\mathrm{w}}$ values obtained for each gel are presented in Table 2. It is clear from the results that high degrees of cross-linking lead to reduced $D_{\mathrm{w}}$, showing that swelling is less favourable when the TPGDA concentration is higher.

Moreover, the $D_{\mathrm{w}}$ values presented in Table 2 show differences from the values reported in the literature (Khaw et al., 1976). For example, pHEMA hydrogels with $26 \%$ water and $1 \%(\mathrm{v}, \mathrm{v})$ ethyleneglycol dimethacrylate in the feed mixture yield a $D_{\mathrm{w}}$ of $2.4 \times 10^{-11} \mathrm{~m}^{2} \mathrm{~s}^{-1}$. The differences 
can be related to factors such as the initiator nature, cross-linking agent and its concentration and water content (Trigo et al., 1994).

\subsubsection{Aqueous solutions at different $p H$ values}

Fig. 1 also shows the effect of $\mathrm{pH}$ on the equilibrium swelling of pHEMA gels at $25^{\circ} \mathrm{C}$. For $\mathrm{pH} 2.0$ (curve D) a slight decrease in $W_{\infty}$ is observed. This can be explained by the reduction of the solvent power of water by the chloride counterion which makes solvent/polymer interactions weaker and favours hydrophobic interactions between polymeric chains (Refojo, 1967; Warren and Prins, 1972). As a consequence, a

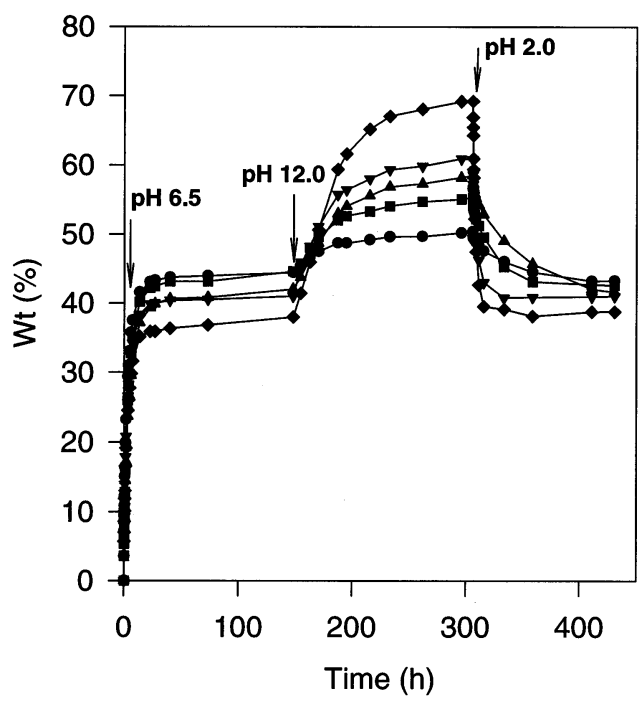

Fig. 2. Dynamic swelling behaviour of pHEMA gels with different concentrations of cross-linker agent (TPGDA), in different $\mathrm{pH}$ solutions, at $25^{\circ} \mathrm{C}$. Data are for pHEMA gels with $1 \mathrm{~mol} \%$ ( ), $2 \mathrm{~mol} \%(\boldsymbol{\square}), 3 \mathrm{~mol} \%(\boldsymbol{\Delta}), 5 \mathrm{~mol} \%$ ( $)$ and $10 \mathrm{~mol} \%$

\section{Table 2}

Values of the apparent diffusion coefficient for water uptake $\left(D_{\mathrm{w}}\right)$ into pHEMA gels cross-linked with different concentrations of TPGDA

\begin{tabular}{ll}
\hline Gel & $D_{\mathrm{w}}\left(\mathrm{m}^{2} \mathrm{~s}^{-1}\right)$ \\
\hline pHEMA1 & $6.1 \times 10^{-11}$ \\
pHEMA2 & $5.0 \times 10^{-11}$ \\
pHEMA4 & $3.8 \times 10^{-11}$ \\
pHEMA5 & $3.2 \times 10^{-11}$ \\
\hline
\end{tabular}

tighter polymeric network is formed, showing lower swelling levels.

In the same figure, curve $A$ shows a large increase in the swelling when the pHEMA gels are immersed in an aqueous $\mathrm{NaOH}$ solution, $\mathrm{pH}$ 12.0. Relatively to the swelling behaviour in distilled water, a $\mathrm{pH} 12.0$ solution induces equilibrium swelling transitions from approximately 48 to $55 \%$, for the lowest concentration of TPGDA (1 $\mathrm{mol} \%$ ), and from 40 to $80 \%$ for the highest concentration $(10 \mathrm{~mol} \%)$. At the same time, from Fig. 2 we can observe that the $W_{\infty}$ at $\mathrm{pH} 12.0$ is attained between 75 and $145 \mathrm{~h}$ depending on the degree of cross-linking of the gel.

As far we know, such a marked dependence of the pHEMA gel equilibrium swelling ratio on $\mathrm{pH}$ has never previously been reported in the literature. For the pHEMA gels crosslinked with ethyleneglycol dimethacrylate $(0.5 \% \mathrm{~mol})$ Brannon-Peppas and Peppas (1991) described only a slight increase in equilibrium swelling values, at $\mathrm{pH}$ between 6.0 and 8.0, which was constant for $\mathrm{pH}$ up to 12.0. The slight dependence on $\mathrm{pH}$ was explained by a delocalization of the electron density on the single bond oxygen to the electron-attracting carbonyl group. As presented in Fig. 1, this agrees with the slight increase of $W_{\infty}$ in pHEMA gels, at pH 10.0 (curve B).

However, a distinct behaviour was found in the present work for the pHEMA gels crosslinked with TPGDA (using a wide range of crosslinking agent concentration from 1 to $10 \mathrm{~mol} \%$ ) at $\mathrm{pH}$ 12.0 (curve A). The gels prepared with high crosslinking content $(5-10 \mathrm{~mol} \%)$, present a high $W_{\infty}$, nearly twice the value obtained for the same gels when immersed in distilled water. To understand these results the pHEMA gels were structurally characterised by FTIR and DSC measurements, after equilibrium at different $\mathrm{pH}$ values. The FTIR spectra of pHEMA gels with different cross-link densities after equilibrium at $\mathrm{pH} 6.5$ (A1, A2) and at $\mathrm{pH} 12.0$ (B1, B2) are shown in Fig. 3. Taking into account the overlap in the contribution of the different bands from TPGDA and HEMA, the most important bands from pHEMA are at: $3400 \quad[v(\mathrm{OH})], 2990$ [v $\left.\left(\mathrm{CH}_{3}\right) \mathrm{as}, v\left(\mathrm{CH}_{2}\right) \mathrm{as}\right], 2959\left[v\left(\mathrm{CH}_{2}\right) \mathrm{s}, \quad v\left(\mathrm{CH}_{3}\right) \mathrm{s}\right]$, $2882\left[\delta\left(\mathrm{CH}_{3}\right)\right], 1726 \quad[v(\mathrm{C}=\mathrm{O})], 1484\left[\delta\left(\mathrm{CH}_{2}\right)\right]$, 


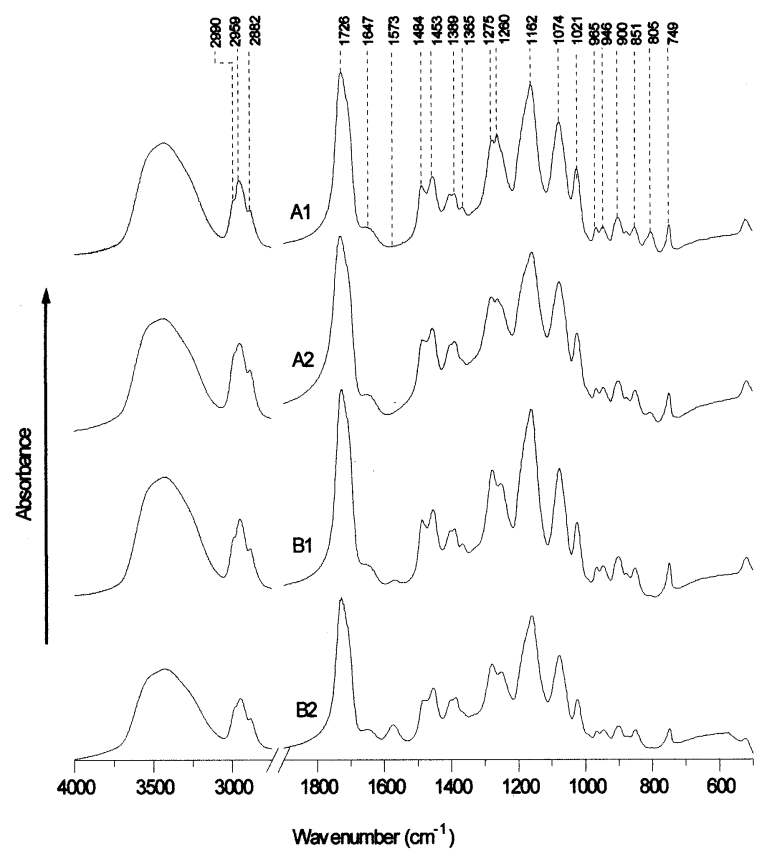

Fig. 3. FTIR spectra of pHEMA gels with $1 \mathrm{~mol} \%$ (A1, B1) and $10 \mathrm{~mol} \%(\mathrm{~A} 2, \mathrm{~B} 2)$ of TPGDA after equilibrium at $\mathrm{pH} 6.5$ (A1, A2) and pH 12.0 (B1, B2).

$1453\left[\delta\left(\mathrm{CH}_{2}\right), \delta\left(\mathrm{CH}_{3}\right) \mathrm{as}\right], 1389\left[\delta\left(\mathrm{CH}_{3}\right) \mathrm{s}\right], 1365$ $\left[\omega\left(\mathrm{CH}_{2}\right)\right], 1275\left[\omega\left(\mathrm{CH}_{2}\right), \delta(\mathrm{CH})\right], 1260[v(\mathrm{C}-\mathrm{O})]$, $1162[\gamma(\mathrm{CH} 3), \tau(\mathrm{OH})], 1074[v(\mathrm{O}-\mathrm{C})$, alcohol], $1021\left[v(\mathrm{C}-\mathrm{O})\right.$, ester], 965-805 [ $v(\mathrm{C}-\mathrm{C}), \gamma\left(\mathrm{CH}_{3}\right)$, $\left.\gamma\left(\mathrm{CH}_{2}\right)\right]$ and $749\left[\delta(\mathrm{O}=\mathrm{C}-\mathrm{O}] \mathrm{cm}^{-1}\right.$ (Faria et al., 1991; Kulbida et al., 1995). Here, $v$ is the bond stretching; $\delta$, the bending; $\omega$, the wagging; $\gamma$, the rocking and $\tau$, the torsion.

In a general view, the spectra of pHEMA gels after the equilibrium at $\mathrm{pH} 6.5$ and 12.0 are similar, with the exception of a peak at 1573 $\mathrm{cm}^{-1}$ in spectra B1 and B2, which can be assigned to the stretching of the COO- group (Zalipsky et al., 1983). As it can be seen, the intensity of this peak increases as a function of crosslinking density (this linear behaviour was maintained for the other gels). Probably, the increase of the intensity is related to the slight hydrolysis of the pHEMA network, at $\mathrm{pH} 12.0$, which is favoured by the increase of cross-linker concentration. FTIR studies of pHEMA gels after equilibrium in an $\mathrm{NaOH}$ aqueous solution at $\mathrm{pH} 10.0$ (results not shown) show the absence of the band at 1573 $\mathrm{cm}^{-1}$, which suggests that are not hydrolysed.

A possible interpretation for the high swelling of pHEMA gels at $\mathrm{pH} 12.0$ would be due to ionisation of the hydroxyl groups on the main network chains. In the literature, the $\mathrm{p} K_{\mathrm{a}}$ values of these hydroxyl groups are reported as being between 11 and 12 (Morrison and Boyd, 1983). The creation of negative charges favours the formation of ionic bonds with counterions as $\mathrm{Na}^{+}$, which could contribute for the increase of ionic strength within the gel. Thus, either the repulsion between ionised individual chains and ionised carbonyl groups from cross-linker chains (particularly in the highly crosslinked gels) or the Donnan potential increase could explain the $W_{\infty}$ increase, displayed by pHEMA gels at pH 12.0 (Ferreira et al., 1999). In addition, as it was shown by FTIR studies, some hydrolysis of HEMA or TPGDA groups, especially for the highly crosslinked gels, can also contribute to the $\mathrm{W} \infty$ increase. Such a relationship between swelling and ionic gradient was checked by transferring pHEMA gels at equilibrium, in aqueous $\mathrm{NaOH}$ solution at $\mathrm{pH}$ 12.0, to distilled water at $\mathrm{pH}$ 6.5. The results obtained for pHEMA2 and pHEMA4 showed an increase in the swelling from 67.7 to $78 \%$ for pHEMA 2 and from 72.8 to $84.0 \%$ for pHEMA4.

Table 1 shows the thermal parameters obtained for the pHEMA gels, after the equilibrium in distilled water and in aqueous $\mathrm{NaOH}$ solution at $\mathrm{pH}$ 12.0. Comparing the respective values of $T_{\mathrm{m}}$ and $\Delta H_{\mathrm{f}}$, it seems that, after the equilibrium at $\mathrm{pH} 12.0$, there is almost complete destruction of the crystalline zones, suggesting a more open structure. The decrease in $\Delta H_{\mathrm{f}}$ with the increase of the crosslinker content can be justified by the high swelling presented by the highly crosslinked pHEMA gels.

When the pHEMA gels were removed from the equilibrium situation in aqueous $\mathrm{NaOH}$ solution at $\mathrm{pH} 12.0$ and transferred to an aqueous $\mathrm{HCl}$ solution at $\mathrm{pH} 2.0$ they shrunk. In the case of the pHEMA4 and pHEMA5 gels the deswelling rate was considerably faster than the swelling rate at $\mathrm{pH}$ 12.0. This agrees with the behaviour observed for poly(2-hydroxyethyl methacrylate-comethacrylic acid) gels crosslinked with $0.45 \mathrm{~mol} \%$ of ethyleneglycol dimethacrylate, when the $\mathrm{pH}$ 
was increased from 4.0 to 7.0 and then decreased from 7.0 to 4.0 , where the observed deswelling rate was faster than the swelling rate (Khare and Peppas, 1995).

From Table 1, the crystallinity of pHEMA gels is recovered after transferring all the gels from $\mathrm{pH}$ 12.0 aqueous solution to $\mathrm{pH} 2.0$ aqueous solution (the lower $T_{\mathrm{g}}$ values for the gels after equilibrium at $\mathrm{pH} 6.5$ than for the same gels at $\mathrm{pH} 2.0$ could be related to an incomplete dryness). This was also confirmed with FTIR studies, where the disappearance of the $1573 \mathrm{~cm}^{-1}$ peak (results not shown) reveals the recovery of the structure presented by the gels at $\mathrm{pH} 6.5$.

The swelling behaviour of the pHEMA gels was also studied in aqueous solutions at different $\mathrm{pH}$ 's containing SA. In Table 3, the equilibrium volume swelling ratio is presented as a function of the crosslinker concentration. The experiment was performed in aqueous $\mathrm{NaOH}$ solution at $\mathrm{pH} 12.0$ containing $0.1 \%(\mathrm{w}, \mathrm{v})$ of $\mathrm{SA}$, and in an aqueous solution of SA dissolved in distilled water $(\mathrm{pH}$ 2.5) with the same concentration of the drug. From these results, practically no effect is observed from the presence of the SA in the different aqueous solutions when compared to the results obtained in the absence of the drug.

\subsection{Salicylic acid release studies}

The dependence of equilibrium swelling ratio on the $\mathrm{pH}$ for the pHEMA gels, in particular those prepared with high TPGDA concentrations, suggested the possibility to use them as controlled release systems sensitive to an external stimulus.

For the release studies, SA was used as a model drug for various reasons, in particular for its importance in pharmaceutical and food technology application. The SA is employed externally on the skin, where it exerts a slight antiseptic action and a marked keratolytic action. The latter property makes salicylic acid a beneficial agent in the local treatment of warts, corns, fungous infections, and certain forms of eczematoid dermatitis. Salicylic acid is also used as preservative of food products in several countries (Abounassif et al., 1994). Secondly, SA is soluble in water at $0.22 \%$ $(\mathrm{w} / \mathrm{v})$. In the presence of alkaline solutions the SA can change to its salts: monosodium salicylate (pH 9.0) and disodium salicylate $(\mathrm{pH}$ 13.5) (Shane and Routh, 1967). Thirdly, its release into water can be conveniently followed by spectrophotometric measurements at $300 \mathrm{~nm}$.

\subsubsection{Swelling in distilled water, loading of $S A$ at} $p H 2.5$, release in distilled water

In Fig. 4 the fractional release of $\mathrm{SA}, F_{\mathrm{SA}}$, is plotted versus (time) $)^{1 / 2},(t)^{1 / 2}$. For a short time period of drug release, $F_{\mathrm{SA}}<0.6$, FSA is linear with $(t)^{1 / 2}$. Since the drug delivery shows a Fickian diffusion mechanism, the expression used for SA release, through pHEMA gels, can be similar to that used for the fractional swelling due to water uptake (Eq. (2)):

Table 3

Equilibrium volume swelling ratio, $Q$, in pHEMA gels swollen in aqueous $\mathrm{NaOH}$ solution at pH 12.0 with or without $\mathrm{SA}$ and in aqueous $\mathrm{HCl}$ solution at $\mathrm{pH} 2.0$ with or without SA

\begin{tabular}{|c|c|c|c|c|c|}
\hline \multirow[t]{3}{*}{ Gel } & \multirow[t]{3}{*}{ TPGDA $(\mathrm{mol} \%)$} & \multicolumn{2}{|c|}{ Equilibrium volume swelling ratio, $Q$} & \multirow{2}{*}{\multicolumn{2}{|c|}{$\mathrm{pH} 2.0$}} \\
\hline & & \multicolumn{2}{|l|}{$\mathrm{pH} 12.0$} & & \\
\hline & & With SA & Without SA & With SA & Without SA \\
\hline pHEMA1 & 1 & 2.56 & 2.18 & 2.09 & 1.81 \\
\hline pHEMA2 & 2 & 2.79 & 3.09 & $-{ }^{a}$ & $-^{\mathrm{a}}$ \\
\hline pHEMA3 & 3 & 3.39 & 3.31 & 1.31 & 1.51 \\
\hline pHEMA4 & 5 & a & $-{ }^{\mathrm{a}}$ & 1.42 & 1.72 \\
\hline pHEMA5 & 10 & 4.97 & 4.99 & 1.44 & 1.42 \\
\hline
\end{tabular}

\footnotetext{
a Not determined.
} 


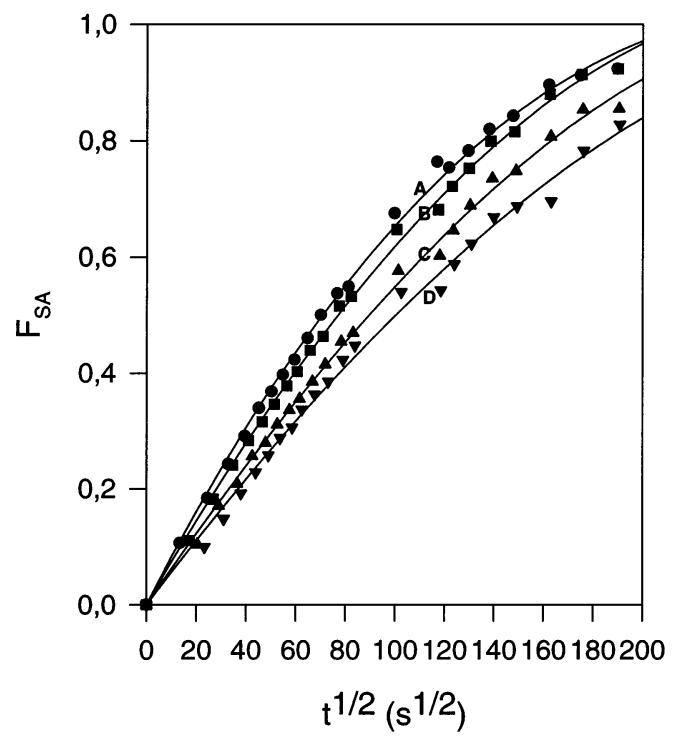

Fig. 4. Fractional release of $\mathrm{SA}\left(F_{\mathrm{SA}}\right)$ versus $(t)^{1 / 2}$ from preswollen pHEMA gels: pHEMA1, A, (2.4 mm thickness, $15.2 \mathrm{~mm}$ diameter); pHEMA3, B, (2.2 mm thickness, $14.4 \mathrm{~mm}$ diameter); pHEMA4, C, (1.8 $\mathrm{mm}$ thickness, $15.5 \mathrm{~mm}$ diameter) and pHEMA5, D, (1.9 mm thickness, $16.0 \mathrm{~mm}$ diameter). The loading of SA $(0.1 \%)$ was made at $\mathrm{pH} 2.5$ and the release in distilled water, at $37^{\circ} \mathrm{C}$.

$F_{\mathrm{SA}}=M_{t} / M_{\infty}=4\left(D_{\mathrm{SA}} t / l_{\mathrm{o}}^{2} \pi\right)^{1 / 2}$

Here, $M_{t}$ and $M_{\infty}$ are the amount of drug released at time $t$ and the maximum amount of SA released, respectively; $D_{\mathrm{SA}}$ is the apparent diffusion coefficient for SA release from the hydrogel and $l_{\mathrm{o}}$ is the thickness of the drug-loaded gel. In accordance with Eq. (3) the slope of this plot yields $D_{\mathrm{SA}}$.

The apparent diffusion coefficients $D_{\mathrm{SA}}$ obtained for all the gels studied, presented in Table 4 , were between $5.3 \times 10^{-11} \mathrm{~m}^{2} \mathrm{~s}^{-1}$ for pHEMA
1 gel and $1.7 \times 10^{-11} \mathrm{~m}^{2} \mathrm{~s}^{-1}$ for pHEMA5 gel. As it can be seen, there is a decrease of $D_{\mathrm{SA}}$ values, and consequently a slower SA release, with increasing degree of cross-linking. Also, from the $t_{50}$ values, which refers to the time required to release $50 \%$ of the solute, a double increase of the $t_{50}$ was observed from pHEMA1 to pHEMA5 gel.

The diffusion coefficient, $D_{\mathrm{SA}}$, is a function of the polymer chain mobility, the average pore size and the mobility of the solvent in the gel (Teijon et al., 1997). The $D_{\mathrm{SA}}$ diminution between pHEMA1 and pHEMA3 can be related essentially to the reduction in polymer chain mobility caused by cross-linking which reduces the average pore size. As it was reported in swelling studies (Section 3.1) for this TPGDA concentration range, the diffusion of SA occurs mainly by a pore flow mechanism.

For pHEMA4 and pHEMA5, as described previously (Wisniewski et al., 1976), the diffusion occurs mainly by a SA aqueous solution/matrix interaction. In this case, the reduction of $D_{\mathrm{SA}}$, compared to the values obtained for pHEMA1 and pHEMA3, is related to the decrease of the non-bounded water and the increase of the percentage of water bounded. SA, as a hydrophilic solute, diffuses mainly through the non-bounded water so the effect of increasing the cross-linker content is to reduce the effective free volume of the polymer matrix. Besides, if diffusion is occurring by an interaction of aqueous solution/matrix, in these gels, the cross-linking density would not be expected to have a significant effect on the apparent diffusion coefficient. Our results for pHEMA4 and pHEMA5 gels, presented in Table 4, show that the apparent diffusion coefficient does not change significantly with crosslinker con-

Table 4

Values of the apparent diffusion coefficient for SA release $\left(D_{\mathrm{SA}}\right), t_{50}$ values and SA load $(A)$, from pHEMA gels with different cross-linker concentrations ${ }^{\mathrm{a}}$

\begin{tabular}{lcccc}
\hline Gel & TPGDA $(\% \mathrm{~mol})$ & $t_{50}(\mathrm{~min})$ & $D_{\mathrm{SA}}\left(\mathrm{m}^{2} \mathrm{~s}^{-1}\right)$ & $A\left(\mathrm{~kg} \mathrm{~m}^{-3}\right)$ \\
\hline pHEMA1 & 1 & 82.0 & $5.3 \times 10^{-11}$ & 6.1 \\
pHEMA3 & 3 & 99.0 & $4.0 \times 10^{-11}$ & 7.4 \\
pHEMA4 & 5 & 132.0 & $2.0 \times 10^{-11}$ & 8.8 \\
pHEMA5 & 10 & 167.0 & $1.7 \times 10^{-11}$ & 10.3 \\
\hline
\end{tabular}

\footnotetext{
${ }^{\text {a }}$ The loading of SA $(0.1 \%)$ was made at $\mathrm{pH} 2.5$ and the release in distilled water, at $37^{\circ} \mathrm{C}$.
} 


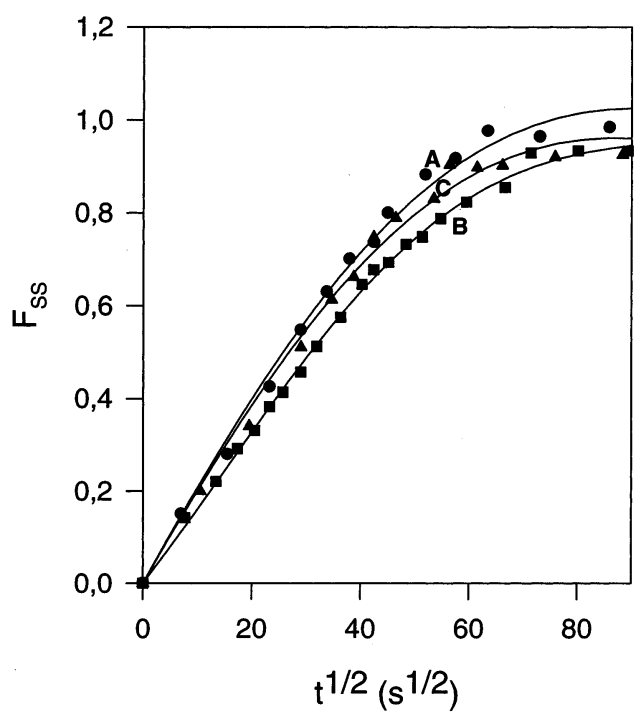

Fig. 5. Fractional release of sodium salicylate $(\mathrm{SS})\left(F_{\mathrm{SS}}\right)$ versus $(t)^{1 / 2}$ from preswollen pHEMA gels: pHEMA1, A, $(2.3 \mathrm{~mm}$ thickness, $17.2 \mathrm{~mm}$ diameter); pHEMA2, B, (2.8 $\mathrm{mm}$ thickness, $17.9 \mathrm{~mm}$ diameter) and pHEMA5, C, (3.3 $\mathrm{mm}$ thickness, $21.4 \mathrm{~mm}$ diameter). The loading of SS $(0.1 \%)$ was made at $\mathrm{pH}$ 12.0 and the release in distilled water, at $37^{\circ} \mathrm{C}$.

centration supporting the idea that the diffusion is not occurring by pore flow in these gels.

The decrease in $D_{\mathrm{SA}}$ values with the degree of cross-linking has previously been observed by Wood et al. (1982) for SA delivery from pHEMA gels. The differences in $D_{\mathrm{SA}}$ values between our work and that of Wood can be ascribed to the different manner in the pHEMA preparation, different crosslinker agents and the $W_{\infty}$ associated to these gels (Garcia et al., 1994).

Taking into account that $M_{\infty}=A V=A S h$ (where $V$ is the disc volume and $S$ its surface area) it was possible to determine the $\operatorname{drug} \operatorname{load}(A)$ for all pHEMA gels (Table 4). The results obtained show that there is a slight increase in the drug loading as the cross-linking density increases, revealing an opposite behaviour as it was showed in $W_{\infty}$ studies (Fig. 1, curve C). Probably, the differences in drug loading can be related to the interactions between the drug and the polymer matrix. These interactions, which are higher when the crosslinking density increases, prevent drug release thus maintaining a (residual) drug concentration within the gel.

\subsubsection{Loading of $S S$ at $p H 12.0$, release in distilled water}

As it was referred previously, the SA, in an aqueous solution of $\mathrm{NaOH}$, is converted to its salt: the sodium salicylate (SS). In Fig. 5 the fractional release of SS, $F_{\mathrm{SS}}$, from pHEMA gels is plotted versus (time $)^{1 / 2},(t)^{1 / 2}$. The apparent diffusion coefficients DSS obtained are presented in Table 5. As it can be seen, the DSS values for all gels are larger when compared to the $D_{\mathrm{SA}}$ values obtained for pHEMA gels when the loading was made at $\mathrm{pH}$ 2.5. Also, the $t_{50}$ values decreases significantly (Table 5). This decrease can be essentially related to the increase of water content (see Fig. 1, curve A). Thus, probably, the increase of diffusion rate can be mainly due to the increase of non-bounded water percentage in the hydrogels water content (Khare and Peppas, 1993).

Also in Table 5, the values of $A$ indicate, unexpectedly, that the drug loading in these conditions is less favourable than when the loading was made at $\mathrm{pH} 2.5$. According to the high $W_{\infty}$ values of pHEMA gels at pH 12.0 (Fig. 1, curve A), a larger drug loading should be expected. Also, from the swelling studies in aqueous solutions at

\section{Table 5}

Values of the apparent diffusion coefficient for SS release $\left(D_{\mathrm{SS}}\right), t_{50}$ values and SS load $(A)$ from pHEMA gels with different cross-linker concentrations ${ }^{\mathrm{a}}$

\begin{tabular}{lllll}
\hline Gel & TPGDA $(\% \mathrm{~mol})$ & $t_{50}(\mathrm{~min})$ & $D_{\mathrm{Ss}}\left(\mathrm{m}^{2} \mathrm{~s}^{-1}\right)$ & $A\left(\mathrm{~kg} \mathrm{~m}^{-3}\right)$ \\
\hline pHEMA1 & 1 & 11.3 & $4.0 \times 10^{-10}$ & 1.06 \\
pHEMA2 & 2 & 15.5 & $4.1 \times 10^{-10}$ & 0.80 \\
pHEMA3 & 3 & 10.4 & $6.7 \times 10^{-10}$ & 0.79 \\
pHEMA5 & 10 & 12.0 & $7.1 \times 10^{-10}$ & 0.81 \\
\hline
\end{tabular}

\footnotetext{
a The loading of SS $(0.1 \%)$ was made at $\mathrm{pH} 12.0$ and the release in distilled water, at $37^{\circ} \mathrm{C}$.
} 


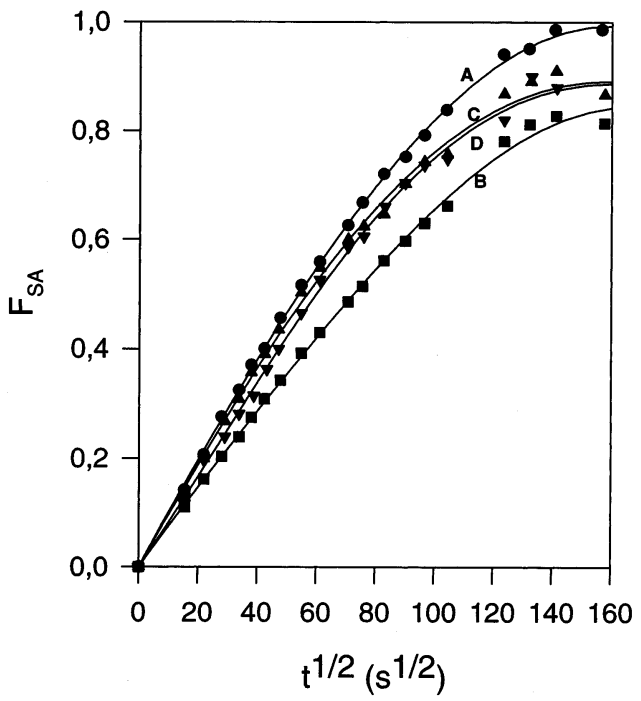

Fig. 6. Fractional release of SA $\left(F_{\mathrm{SA}}\right)$ versus $(t)^{1 / 2}$ from preswollen pHEMA gels: pHEMA1, A, (2.0 mm thickness, $15.6 \mathrm{~mm}$ diameter); pHEMA3, B, (2.5 mm thickness, $15.9 \mathrm{~mm}$ diameter); pHEMA4, C, (2.5 mm thickness, $15.9 \mathrm{~mm}$ diameter) and pHEMA5, D, (3.0 mm thickness, $16.0 \mathrm{~mm}$ diameter). The swelling was made at $\mathrm{pH} 12.0$, the loading of SA $(0.1 \%)$ at $\mathrm{pH} 2.5$ and the release in distilled water, at $37^{\circ} \mathrm{C}$.

different $\mathrm{pH}$ values, either in the presence or absence of SA (Table 3), no effect in swelling was observed for either case. The phenomenon can be explained taking into account the fact that at $\mathrm{pH}$ 12.0 the pHEMA gels become ionisable, establishing ionic bonds with sodium ion and thus favouring mainly the sorption of the water. The entrance of the drug, in its salt form, will be allowed until the equilibrium between the drug concentration inside and outside of the gel is reached, thus respecting the Donnan potential.
3.2.3. Swelling at $p H$ 12.0, loading of $S A$ at $p H$ 2.5 , release in distilled water

Fig. 6 shows the fractional release of SA, $F_{\mathrm{SA}}$, from pHEMA gels, and in Table 6, the values of the apparent diffusion coefficient for SA release $\left(D_{\mathrm{SA}}\right), t_{50}$ values and SA load $(A)$ are presented. The $D_{\mathrm{SA}}$ values for all gels are larger when compared to the $D_{\mathrm{SA}}$ values obtained for gels swelled at $\mathrm{pH} 6.5$ and loaded at $\mathrm{pH} 2.5$, mainly for highly crosslinked gels. Based on the dynamic swelling data showed in Fig. 2, we observe that after 8 days the $W_{\infty}$ of pHEMA gels at $\mathrm{pH} 2.0$ is identical or even lower than the swelling exhibited for the same gels at $\mathrm{pH}$ 6.5. It would be expected that the SA release behaviour of gels under these conditions would be practically the same, as was observed for the same gels when the swelling was made at $\mathrm{pH} 6.5$ and loading at $\mathrm{pH}$ 2.5. Instead, the behaviour of the gels is intermediate between the behaviour exhibited when the swelling was undertaken at $\mathrm{pH} 6.5$ and loading $\mathrm{pH} 2.5$, and when the swelling and loading were made at $\mathrm{pH}$ 12.0. A possible interpretation involves an interference of the drug in the water desorption mechanism, changing, consequently, the SA release behaviour from pHEMA gels.

\subsubsection{Swelling and loading of SS at pH 12.0, release at $\mathrm{pH} 2.0$}

Fig. 7 presents the results of the fractional release of $\mathrm{SS}, F_{\mathrm{SS}}$, from pHEMA gels when the swelling and loading of SS is undertaken at $\mathrm{pH}$ 12.0 and the release at $\mathrm{pH}$ 2.0. Since, the dimensions of pHEMA gels studied change significantly with time, it was not possible to calculate the apparent diffusion coefficient, $D_{\mathrm{SS}}$ (Blanco et al., 1994). The $t_{50}$ values obtained for pHEMA1,

Table 6

Values of the apparent diffusion coefficient for SA release $\left(D_{\mathrm{SA}}\right), t_{50}$ values and SA load $(A)$, from pHEMA gels with different cross-linker concentrations ${ }^{\mathrm{a}}$

\begin{tabular}{lllll}
\hline Gel & TPGDA $(\% \mathrm{~mol})$ & $t_{50}(\mathrm{~min})$ & $D_{\mathrm{SA}}\left(\mathrm{m}^{2} \mathrm{~s}^{-1}\right)$ & $A\left(\mathrm{~kg} \mathrm{~m}^{-3}\right)$ \\
\hline pHEMA1 & 1 & 47.0 & $6.5 \times 10^{-11}$ & 5.5 \\
pHEMA3 & 3 & 86.0 & $5.5 \times 10^{-11}$ & 4.5 \\
pHEMA4 & 5 & 52.0 & $9.3 \times 10^{-11}$ & 4.2 \\
pHEMA5 & 10 & 60.0 & $1.3 \times 10^{-11}$ & 4.1 \\
\hline
\end{tabular}

\footnotetext{
${ }^{\text {a }}$ The swelling was made at $\mathrm{pH} 12.0$, the loading of SA $(0.1 \%)$ at $\mathrm{pH} 2.5$ and the release in distilled water, at $37^{\circ} \mathrm{C}$.
} 


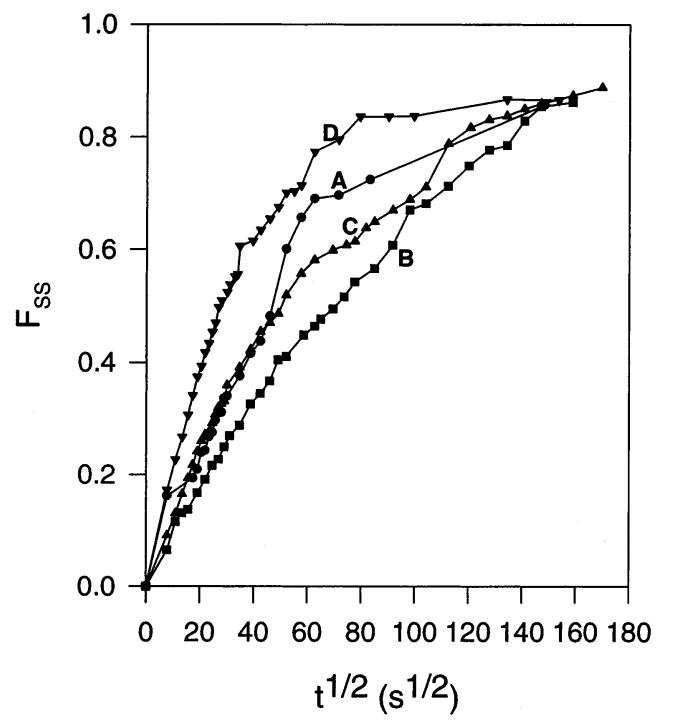

Fig. 7. Fractional release of $\mathrm{SS}\left(F_{\mathrm{SS}}\right)$ versus $(t)^{1 / 2}$ from preswollen pHEMA gels: pHEMA1, A, (2.0 mm thickness, $17.7 \mathrm{~mm}$ diameter); pHEMA2, B, (2.6 mm thickness, $18.6 \mathrm{~mm}$ diameter); pHEMA3, C, (2.3 $\mathrm{mm}$ thickness, $18.5 \mathrm{~mm}$ diameter) and pHEMA5, D, (3.6 mm thickness, $21.0 \mathrm{~mm}$ diameter). The loading of SS $(0.1 \%)$ was made at $\mathrm{pH} 12.0$ and the release in an aqueous solution at $\mathrm{pH} 2.0$, at $37^{\circ} \mathrm{C}$.

pHEMA2, pHEMA3 and pHEMA5 gels were 40.0, 79.0, 40.0 and $12.0 \mathrm{~min}$, respectively. These values are larger than the $t_{50}$ values in the release experiments of SS in distilled water. Thus, during the drug release the polymer matrix would close allowing larger release times. In the curve profile it is possible to observe some inflexion points which can be related to the structural rearrangement promoted by the $\mathrm{pH}$ variation.

\section{Conclusions}

In the present study, various pHEMA gels with different crosslinking density were examined. On the basis of equilibrium and dynamic swelling data we have demonstrated that the water uptake of pHEMA gels is governed by the degree of crosslinking and by the external $\mathrm{pH}$. The pHEMA gels, especially those prepared with the highest concentrations of crosslinking agent, showed an exceptional $\mathrm{pH}$-sensitivity. These results can be explained by considering the Donnan potential increase resulting from the ionic bonds established with sodium ions.

The SA release studies showed that changing the $\mathrm{pH}$ in swelling, drug loading or drug release could provide control of the drug release rate and drug loading. When the swelling and drug loading of pHEMA gels is performed at neutral or acidic $\mathrm{pH}$, the release process is slower and the drug load capacity is larger than when these operations are made at basic $\mathrm{pH}$.

\section{Acknowledgements}

The authors wish to thank FCT, Portugal, for the grant FMRH//4413 to Lino Ferreira, and Professor Rui Fausto for helping in the FTIR spectra assignment.

\section{References}

Abounassif, M.A., Mian, M.S., Mian, N.A.A., 1994. Salicylic acid. In: Analytical Profiles of Drug Substances and Excipients, vol. 23. Academic Press, New York, pp. 421-470.

Allen, P.E.M., Bennett, D.J., Williams, D.R.G., 1992. Water in methacrylates-I. Sorption and desorption properties of poly(2-hydroxyethyl methacrylate-co-glycol dimethacrylate) networks. Eur. Polym. J. 28 (4), 347-352.

Bettini, R., Colombo, P., Peppas, N.A., 1995. Solubility effects on drug transport through $\mathrm{pH}$-sensitive, swelling-controlled release systems: transport of theophyline and metoclopramide monohydrochloride. J. Controlled Rel. 37, 105111.

Blanco, M.D., Rego, J.M., Huglin, M.B., 1994. Drug release with simultaneous dimensional changes from a new copolymeric hydrogel. Polymer 35 (16), 3487-3491.

Brannon-Peppas, L., Peppas, N.A., 1991. Equilibrium swelling behaviour of dilute ionic hydrogels in electrolytic solutions. J. Controlled Rel. 16, 319-330.

Corkhill, P.H., Jolly, A.M., Ng, C.O., Tighe, B.J., 1987. Synthetic hydrogels: 1. Hydroxyalkyl acrylate and methacrylate copolymers-water binding studies. Polymer 28, $1758-1766$.

Crank, J., 1975. The Mathematics of Diffusion, second ed. Clarendon, Oxford.

Denizli, A., Kiremitci, M., Piskin, E., 1988. Subcutaneous polymeric matrix system poly(HEMA-BGA) for controlled release of an anticancer drug (5-fluorouacil). Biomaterials 9, $363-366$.

Faria, M.D.G., Teixeira-Dias, J.J.C., Fausto, R., 1991. Conformational stability for methyl acrylate: a vibrational spectroscopic and ab initio MO study. Vibrat. Spectrosc. 2, 43-60. 
Ferreira, L., Vidal, M.M., Geraldes, C.F.G.C., Gil, M.H., 1999. Preparation and characterisation of gels based on sucrose modified with glycidyl methacrylate. Carbohydrate Polymers (in press).

Garcia, O., Trigo, R.M., Blanco, M.D., Teijon, J.M., 1994. Influence of degree of crosslinking on 5-fluorouacil release from poly(2-hydroxyethyl methacrylate) hydrogels. Biomaterials 15 (9), 689-694.

Garner, A., Sugden, J.K., 1973. A rapid method for the simultaneous estimation of acetyl salicylic and salicylic acids in body fluids. Anal. Lett. 6 (4), 275-279.

Huglin, M.B., Sloan, D.J., 1983. Release of ergotamine from poly(2-hydroxyethyl methacrylate). Br. Polym. J. 15, 165171.

Khare, A.R., Peppas, N.A., 1993. Investigation of hydrogel water in polyelectrolyte gels using differential scanning calorimetry. Polymer 34 (22), 4736-4739.

Khare, A.R., Peppas, N.A., 1995. Swelling/deswelling of anionic copolymer gels. Biomaterials 16 (7), 559-567.

Khaw, B., Ratner, B.D., Hoffman, A.S., 1976. The thermodynamics of water sorption in irradiation-grafted hydrogels. In: Andrade, J.D. (Ed.), Hydrogels for Medical and Related Applications, ACS Symposium Series 31, vol. 31. American Chemical Society, Washington, pp. 295-304.

Kulbida, A., Ramos, M.N., Rasanen, M., Schrems, O., Fausto, R., 1995. Rotational isomerism in acrylic acid. J. Chem. Soc. Faraday Trans. 91 (11), 1571-1585.

Montheard, J.P., Chatzopoulos, M., Chappard, D., 1992. 2Hydroxyethyl methacrylate (HEMA): chemical properties and applications in biomedical fields. J.M.S. - Rev. Macromol. Chem. Phys. C32 (1), 1-34.

Morrison, R., Boyd, R., 1983. Organic Chemistry, 9th edition. Fundação Calouste Gulbenkian, Lisboa.

Peluso, G., Petillo, O., Anderson, J.M., Ambrosio, L., Nicolais, L., Melone, M.A.B., Eschbach, F.O., Huang, S.J., 1997. The differential effects of poly(2-hydroxyethyl methacrylate) and poly(2-hydroxyethyl methacrylate)/ poly(caprolactone) polymers on cell proliferation and collagen synthesis by human lung fibroblasts. J. Biomed. Mater. Res. 34, 327-336.
Ratner, B.D., Hoffman, A.S., 1976. Synthetic hydrogels for biomedical applications. In: Andrade, J.D. (Ed.), Hydrogels for Medical and Related Applications, ACS Symposium Series 31, vol. 31. American Chemical Society, Washington, pp. 1-36.

Refojo, M.F., 1967. Hydrophobic interaction in poly(2-hydroxyethyl methacrylate) homogeneous hydrogel. J. Polym. Sci. 5, 3103-3113.

Refojo, M.F., Yasuda, H., 1965. Hydrogels from 2-hydroxyethyl methacrylate and propylene glycol monoacrylate. J. Appl. Polym. Sci. 9, 2425-2435.

Robert, C.C.R., Buri, P.A., Peppas, N.A., 1985. Effect of degree of crosslinking on water transport in polymer microparticles. J. Appl. Polym. Sci. 30, 301-306.

Shane, N.A., Routh, J.I., 1967. Use of isosbestic point as a base line in differential spectrophotometer. Anal. Chem. $39,414$.

Svecik, S., Vacik, J., Chmelikova, D., Smetana Jr, K., 1995. Surface alkaline hydrolysis of 2-hydroxyethyl methacrylate gels. J. Mater. Sci. Mater. Med. 4, 505-509.

Teijon, J.M., Trigo, R.M., Garcia, O., Blanco, M.D., 1997. Cytarabine trapping in poly(2-hydroxyethyl methacrylate) hydrogels: drug delivery studies. Biomaterials 18 (5), 383388.

Trigo, R.M., Blanco, M.D., Teijon, J.M., Sastre, R., 1994. Anticancer drug, ara-C, release from pHEMA hydrogels. Biomaterials 15 (14), 1181-1186.

Warren, T.C., Prins, W., 1972. Polymer-diluent interaction in cross-linked gels of poly(2-hydroxyethyl methacrylate). Macromolecules 5 (4), 506-512.

Wisniewski, S.J., Gregonis, D.E., Kim, S.W., Andrade, J.D., 1976. Diffusion through hydrogel membranes. 1. Permeation of water through poly(2-hydroxyethyl methacrylate) and related polymers. In: Andrade, J.D. (Ed.), Hydrogels for Medical and Related Applications, ACS Symposium Series 31, vol. 31. American Chemical Society, Washington, pp. 80-87.

Wood, J.M., Attwood, D., Collett, J.H., 1982. The influence of gel formulation on the diffusion of salicylic acid in poly HEMA hydrogels. J. Pharm. Pharmacol. 34, 1-4.

Zalipsky, S., Gilon, C., Zilkha, A., 1983. Attachment of drugs to polyethylene glycols. Eur. Polym. J. 19 (12), 1177-1183. 